\title{
Análise do desempenho da máquina 'slingshot' em subsistemas de colheita em florestas de eucalipto'
}

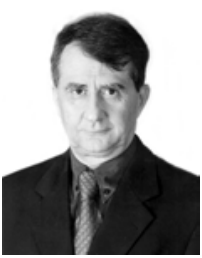

\author{
Amaury P. de Souza ${ }^{2}$, Luciano J. Minette ${ }^{2}$, Fábio M. T. Moreira ${ }^{3}$, Carlos C. Machado² \& Kátia R. Silva ${ }^{4}$ \\ 1 Trabalho desenvolvido com recursos financeiros do CNPq \\ 2 DEF/UFV, CEP 36570-000, Viçosa, MG. Fone: (31) 3899-2466. E-mail: amaurysouza@ufv.br (Foto), minetti@ufv.br \\ e machado@ufv.br \\ ${ }^{3}$ IBAMA, CP 09870, CEP 70818-900, Brasília, DF. Fone: (61) 3161-1594. E-mail: ftieghi@ig.com.br \\ ${ }^{4}$ Grupo Orsa Florestal, CEP 68240-600, Monte Dourado, PA. Fone: (93) 3736-6480. E-mail: krsilva@grupoorsa.com.br
}

Protocolo $160-6 / 11 / 2002$ - Aprovado em 1/3/2004

\begin{abstract}
Resumo: Com este trabalho, objetivou-se avaliar, técnica e economicamente, o 'slingshot' em diferentes subsistemas de colheita em florestas de eucalipto. A análise técnica englobou um estudo de tempos e movimentos e produtividade, e a análise econômica envolveu os parâmetros custo operacional, custo de produção e rendimento energético. O elemento processamento nos subsistemas 1 e 2 consumiu mais da metade do tempo do ciclo operacional; já no subsistema 3 os elementos busca e corte, e processamento representaram, juntos, cerca de $75 \%$ do tempo do ciclo total. Chegou-se ao custo operacional de US\$68,45 ha ${ }^{-1}$ nos subsistemas 1 e 2 e de US\$70,78 ha-1 no subsistema 3. Nos subsistemas 1, 2 e 3 os custos de produção do 'slingshot' foram de US $\$ 1,67 ; 2,02$ e $5,47 \mathrm{~m}^{-3}$ (com casca), respectivamente. O rendimento energético foi de 3,$60 ; 4,37$ e $11,42 \mathrm{~g} \mathrm{~kW}^{-1} \mathrm{~m}^{-3}$ com casca, respectivamente.
\end{abstract}

Palavras-chave: colheita florestal, custo, mecanização florestal

\section{Analysis of the performance of a slingshot machine in subsystems of eucalyptus forest harvesting}

\begin{abstract}
This work had the objective to evaluate technically and economically a slingshot machine in different timber harvesting subsystems in eucalyptus forests. The analysis technique included productivity and a motion and time study. The economic analysis included the parametersoperational cost, production cost, and energy consumption rate. The element processing in subsystems 1 and 2 consumed more than half of the operational cycle time. In the subsystem 3 , the elements searching and cutting trees and processing represented together about $75 \%$ of the total cycle time. The operational cost was US\$68.45 ha $\mathrm{ha}^{-1}$ in the subsystems 1 and 2 and US $\$ 70.78 \mathrm{ha}^{-1}$ in the subsystems 3 . The slingshot production costs were US\$1.67; 2.02 and $5.47 \mathrm{~m}^{-3}$, in the subsystems 1,2 and 3, respectively. The energy consumption rate were 3.60; 4.37 and $11.42 \mathrm{~g} \mathrm{~kW}^{-1} \mathrm{~m}^{-3}$, in the subsystems 1.2 and 3 , respectively.
\end{abstract}

Key words: timber harvesting, logging cost, forest mechanization

\section{INTRODUÇÃO}

Em relação à formação econômica do País, a economia florestal brasileira tem sido responsável, anualmente, por aproximadamente $4 \%$ do Produto Interno Bruto (PIB), gerando 600.000 empregos diretos, US\$ 450 milhões em arrecadação de impostos e US\$ 4,1 bilhões em divisas de exportação (Garlipp,1995).

Para manter a competitividade é necessário aumentar a produtividade e reduzir custos; com isto, a colheita, por ser o item que mais onera o custo de produção da madeira no Brasil (Bagio \& Stohr, 1978, Tanaka, 1986, Machado, 1984, Valverde 2000), precisa ter suas operações otimizadas, de forma que a qualidade seja melhorada, as perdas diminuídas e os custos minimizados.

De acordo com DURATEX (1999), com a abertura das importações, por volta de 1994, boa parte das empresas brasileiras iniciou a mecanização da colheita. Desde então, verifica-se aumento contínuo do nível de mecanização intensa e, em maior escala, na colheita de florestas em primeira rotação, em que $\mathrm{o}$ alto volume por árvore e a homogeneidade da floresta colaboram para sua viabilização. Diz-se ainda que o nível atual de mecanização no País só não é maior devido à difículdade de viabilização em florestas com mais de um fuste por cepa e baixo volume por árvore, normalmente verificada em florestas manejadas com duas ou até três rotações. A colheita da madeira 
com baixo volume por árvore é um dos grandes desafios para os técnicos da área e um dos principais objetos de pesquisa no segmento na atualidade (DURATEX, 1999).

Com o presente trabalho, objetivou-se avaliar, técnica e economicamente, o desempenho do 'slingshot' em diferentes subsistemas de colheita em florestas conduzidas.

\section{MATERIAL E MÉTODOS}

\section{Região de estudo}

A pesquisa foi conduzida em povoamentos florestais de uma empresa do setor, situados na região noroeste do Estado de São Paulo, entre os paralelos $22^{\circ} 55^{\prime}$ de latitude sul, $48^{\circ} 50^{\prime}$ de longitude oeste e a $750 \mathrm{~m}$ de altitude. O solo predominante na região é o Latossolo Vermelho-Escuro (LE), relevo plano a suave ondulado. Conforme a classificação de Koeppen, o clima característico da região é o Cwa, clima quente úmido, de inverno seco. A precipitação média anual é de aproximadamente $1.200 \mathrm{~mm}$, a temperatura média anual se situa em torno de $21^{\circ} \mathrm{C}$ e a umidade relativa média do ar é de $60 \%$.

\section{Descrição do 'slingshot'}

O 'slingshot' analisado neste trabalho se compõe de uma máquina-base, marca Timberjack, modelo 608, motor Cummins, cabeçote de corte da marca Risley, modelo S1821, com capacidade de corte de 21 polegadas e velocidade de desgalhamento de $2,5 \mathrm{~m} \mathrm{~s}^{-1}$, disco de corte com 32 dentes, tempo de corte de 4-5 s e $300 \mathrm{rpm}$, torre de corte de 2,80 m, com rotação lateral de $220^{\circ}$ que tem, como aspecto operacional próprio, a sua capacidade de operação com várias árvores simultaneamente, como ilustra a Figura 1.
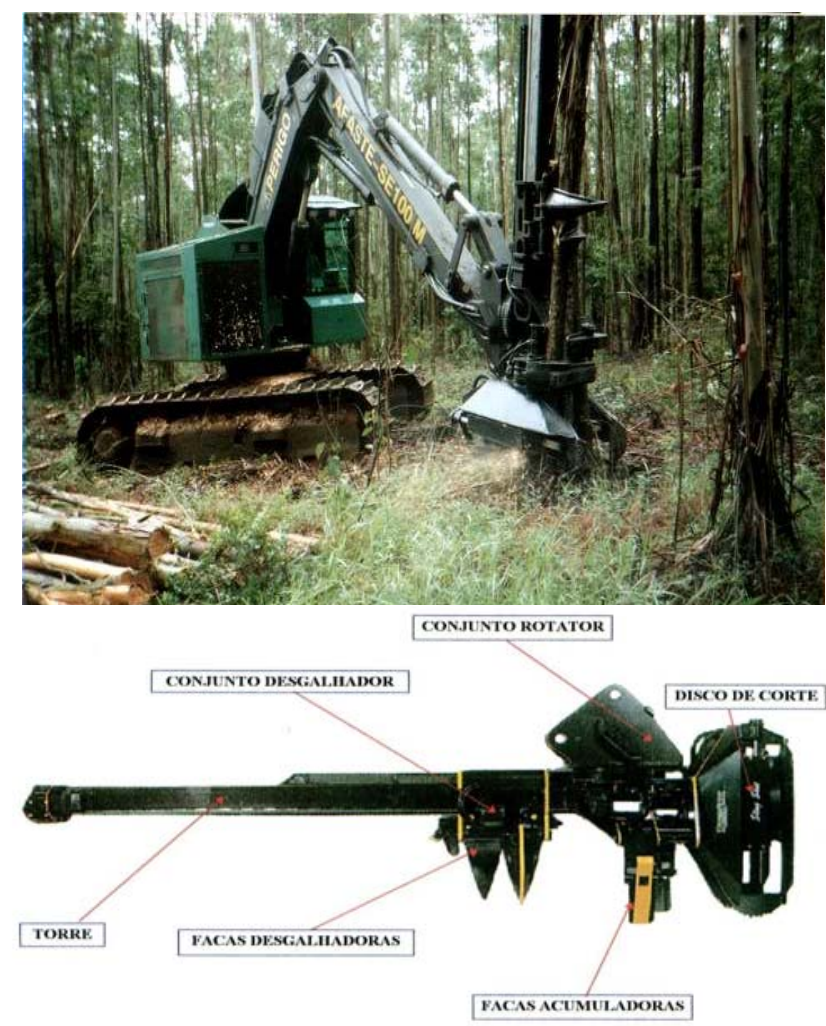

Figura 1. Slingshot estudado neste trabalho

\section{Subsistemas de colheita}

Os subsistemas avaliados foram:

Subsistema 1: O Feller-Buncher iniciava a derrubada direcionando a base dos feixes de árvores para a extremidade do talhão, onde se iniciou o trabalho, formando os feixes a aproximadamente 45 graus em relação ao alinhamento de plantio; depois da derrubada da primeira metade dos dois eitos, deslocava-se para a outra extremidade do talhão iniciando-se, assim, a derrubada da segunda metade do primeiro eito de trabalho e, posteriormente, a derrubada da outra metade do segundo eito. A etapa seguinte foi a extração, com o Skidder, o qual se deslocava da margem da estrada até o local onde se encontravam os feixes; em seguida, acionava-se a abertura das garras da pinça, abaixando-a, prendendo e suspendendo o feixe parcialmente em relação ao solo, iniciando o arraste em direção à margem do talhão, onde o feixe de madeira era posicionado ao lado dos outros. Aproximadamente metade dos feixes era arrastada para uma extremidade do talhão e a outra metade para a extremidade oposta; os feixes na margem do talhão eram dispostos num ângulo de aproximadamente $30^{\circ} \mathrm{em}$ relação ao sentido do alinhamento do plantio. A etapa final deste subsistema consistiu no processamento da madeira, realizado pelo 'slingshot', que se deslocava em uma faixa de $\pm 4 \mathrm{~m}$ entre os feixes arrastados pelo Skidder e as pilhas formadas pela madeira já processada, sendo a galhada depositada entre os feixes arrastados pelo Skidder e a pilha formada na margem do talhão.

Subsistema 2: A derrubada também foi realizada com o FellerBuncher, que derrubava cada um dos dois eitos de trabalho, todos num único sentido, com a base dos feixes direcionada para a extremidade do talhão em que se iniciava a derrubada; os feixes eram direcionados a aproximadamente $30^{\circ} \mathrm{em}$ relação ao alinhamento do plantio; depois, foi realizado o processamento da madeira dentro do talhão, pelo 'slingshot'. A movimentação da máquina foi feita de acordo com o sentido de deslocamento do Feller-Buncher iniciando o processamento pela extremidade do talhão onde o Feller-Buncher finalizou a derrubada do eito. A etapa final deste subsistema consistiu na extração realizada com o Forwarder, que se deslocava sobre a mesma linha de tráfego do 'slingshot', extraindo cada eito de trabalho isoladamente, ou seja, realizando o carregamento apenas por um lado, pelo fato da distância entre as pilhas de cada eito ser maior que o alcance máximo da grua do Forwarder. Metade do comprimento de cada eito de trabalho foi extraída para cada extremidade do talhão, visando otimizar a distância média de extração.

Subsistema 3: A etapa completa de corte (derrubada e processamento) foi realizada pelo 'slingshot', sendo uma faixa de corte de quatro linhas. O 'slingshot' desloca-se sobre a segunda linha, realizando a derrubada da primeira linha por um lado, e da terceira e quarta, por outro, sendo as pilhas formadas após o processamento posicionadas entre a terceira e a quarta linha de corte. A etapa final foi a extração da madeira com o Forwarder, cujo procedimento operacional foi similar ao descrito para o subsistema 2 ; neste caso, no entanto, devido a distância entre as pilhas formadas nos eitos de trabalho ser menor, proporcionavam-se condições para que o carregamento fosse realizado por ambos os lados (direito e esquerdo). Em todos os 
sistemas o comprimento das toras era de $6 \mathrm{~m}$ e a mão-de-obra utilizada foi toda própria.

\section{Coleta de dados}

Segundo a metodologia proposta por Barnes (1968), primeiramente foi realizado um estudo piloto dos subsistemas de colheita analisados, buscando-se definir o número de observações necessárias para proporcionar um erro de amostragem máximo de $5 \%$, por meio da seguinte expressão:

$$
\mathrm{n} \geq \frac{\mathrm{t}^{2}+\mathrm{CV}^{2}}{\mathrm{E}^{2}}
$$

em que:

n - número mínimo de ciclos necessários

t - valor de t, para o nível de probabilidade desejado e (n-1) graus de liberdade

CV - coeficiente de variação, em percentagem

E - erro admissível, em percentagem

Considerando-se o número de observações necessárias e se levando em consideração as faixas de corte normalmente utilizadas pela empresa, definiu-se o tamanho da área a ser explorada por cada subsistema que proporcionasse o número mínimo de observações a serem coletadas. A partir desse ponto, selecionou-se um talhão, que seria explorado na seqüência pela área de colheita florestal; foram, então, alocadas três parcelas de 42 linhas de plantio cada uma; depois de alocadas no campo, com o auxílio da equipe de inventário da empresa, fez-se o inventário, de cada parcela; paralelamente ao inventário realizou-se o censo de cada parcela obtendo-se o número exato de árvores existentes nestas. Com os resultados apresentados na Tabela 1, estratificou-se cada parcela, segundo o volume médio por árvore.

Tabela 1. Características dendrométricas das parcelas

\begin{tabular}{lccccc}
\hline Parcela & $\begin{array}{c}\text { DAP } \\
(\mathrm{cm})\end{array}$ & $\begin{array}{c}\text { Altura } \\
(\mathrm{m})\end{array}$ & $\begin{array}{c}\text { Vol. } \\
\text { ha }^{-1} \mathrm{~m}^{3}\end{array}$ & $\begin{array}{c}\text { Arvores } \\
\text { há }^{-1}\end{array}$ & $\begin{array}{c}\text { Vol. árvore } \\
\mathrm{m}^{3}\end{array}$ \\
\hline A (6,3 ha) & 9,0 & 13,9 & 133,7 & 1375 & 0,054 \\
B (6,3 ha) & 9,7 & 15,2 & 171,3 & 1431 & 0,068 \\
C (6,3 ha) & 10,4 & 15,5 & 189,9 & 1469 & 0,079 \\
\hline DAP - Diâmetro a altura de 1,30 m; Vol - Volume com casca
\end{tabular}

\section{Análise técnica}

A análise técnica do 'slingshot' em cada subsistema analisado, baseou-se nos seguintes parâmetros:

a) Estudo de tempo e movimentos: utilizou-se o método de tempo contínuo; foram utilizados no estudo um cronômetro sexagesimal, uma prancheta e formulários específicos, nos quais foram registrados os dados, os tempos dos elementos do ciclo na forma sexagesimal e, posteriormente, convertidos para a forma centesimal, mais comumente empregada neste tipo de estudo.

b) Produtividade: a produtividade do 'slingshot' foi determinada em metros cúbicos com casca por hora efetiva de trabalho, para cada parcela, sendo a produtividade representativa de cada subsistema a média das três parcelas.

$$
\text { Produtividade }=\frac{\text { número de arvores } \times \text { volume por árvore }}{\text { horas efetivamente trabalhadas }}
$$

número de árvores - foi obtido através de um censo completo realizado a priori, em cada parcela experimental

volume por árvore - é o volume médio por árvore em cada parcela, obtido através do inventário da área

horas efetivamente trabalhadas - são as horas efetivas de trabalho gastas em cada parcela experimental, obtidas por meio do estudo de tempos e movimentos e da coleta das horas efetivas trabalhadas em cada subsistema

\section{Análise econômica}

A análise econômica do 'slingshot' em cada subsistema analisado, baseou-se nos parâmetros seguintes:

a) Custo operacional: os custos operacionais do 'slingshot' foram obtidos diretamente da planilha de custos da empresa em que foi realizado o trabalho, englobando:

- Custos fixos: depreciação, juros e seguros;

- Custos variáveis: combustíveis, lubrificantes e graxas,óleo hidráulico, esteiras, manutenção e reparos, transporte de pessoal e maquinário e custos de pessoal operacional.

$\mathrm{O}$ custo operacional total foi encontrado somando-se os custos fixos e os variáveis mais o custo de administração.

b) Custo de produção: O custo de produção foi obtido pela divisão dos custos operacionais (US\$ ha ${ }^{-1}$ ) pela produtividade $\left(\mathrm{m}^{3}\right.$ com casca ha-1) do 'slingshot', dentro de cada subsistema estudado.

c) Rendimento energético: o rendimento energético foi obtido pela razão entre o consumo específico de combustível $\left(\mathrm{g} \mathrm{kW}^{-1} \mathrm{ha}^{-1}\right)$ e a produtividade com casca $\left(\mathrm{m}^{3} \mathrm{ha}^{-1}\right)$ do 'slingshot', dentro de cada subsistema estudado, tendo sido dado em $\mathrm{g} \mathrm{kW}^{-1} \mathrm{~m}^{3}$ com casca.

\section{RESULTADOS E DISCUSSÃO}

\section{Estudo de tempo e movimentos}

O 'slingshot' desempenhava funções semelhantes nos subsistemas 1 e 2, encontrando-se, desta forma, os mesmos elementos operacionais, representados na Figura 2.

Esses valores correspondem a um ciclo operacional de corte composto de aproximadamente 8,0 e 6,67 árvores em média, nos subsistemas 1 e 2 , respectivamente. Notou-se que o tempo gasto com o elemento processamento em ambos os subsistemas, abrangeu mais da metade do ciclo operacional do 'slingshot', e esses tempos foram muito semelhantes entre os subsistemas 1 e 2 .

Os tempos dos elementos deslocamento do cabeçote vazio e carregado, também foram muito similares nos dois subsistemas, e responsáveis, juntos, por cerca de 14 a 15\% do tempo total do ciclo. Os elementos que apresentaram as maiores diferenças foram os elementos deslocamento da máquina-base, que corresponderam a 4,89 e 10,80\%, nos subsistemas 1 e 2 , respectivamente, e o elemento pega do feixe, que correspondeu a 21,37 e 13,47\%, nos subsistemas 1 e 2, respectivamente.

Em relação ao deslocamento da máquina-base, no subsistema 1 os feixes arrastados pelo Skidder foram posicionados mais próximos uns dos outros em relação ao 


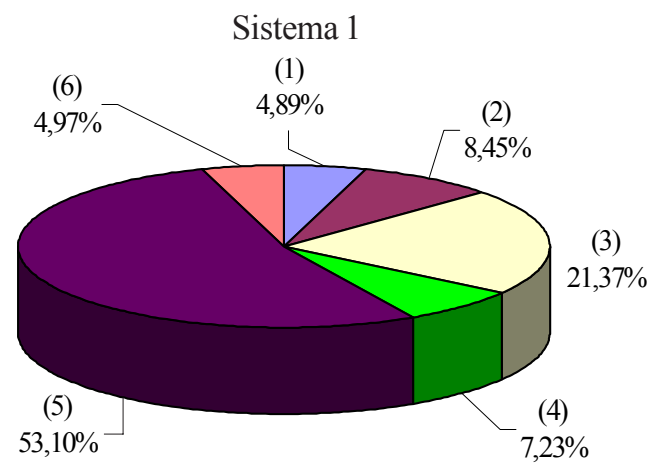

Sistema 2

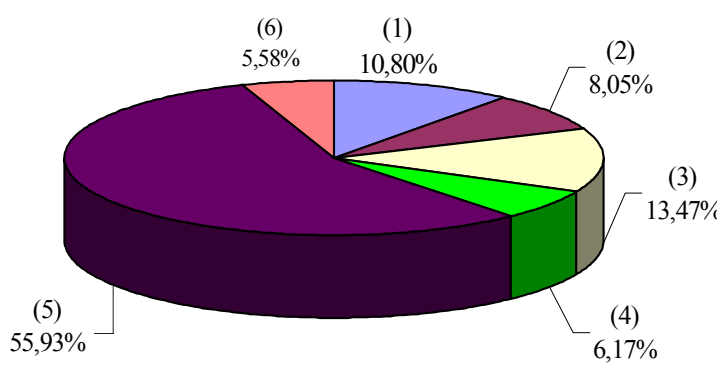

(1) - Deslocamento máquina base; (2) - Deslocamento do cabeçote vazio; (3) - Pega do feixe; (4) - Deslocamento do cabeçote carregado; (5) - Processamento; (6) - Interrupções

Figura 2. Composição percentual do tempo total do ciclo operacional do 'slingshot', nos subsistemas 1 e 2

subsistema 2. Por ser menor a distância entre os feixes era também menor, conseqüentemente, a distância que o slingshot tinha que se deslocar para processar um novo feixe ao terminar o processamento do feixe anterior, resultando em menor tempo de deslocamento da máquina-base, indicando que esse tempo médio de deslocamento da máquina-base teve relação direta com o número médio de árvores em cada parcela pois, quanto maior o número de árvores na parcela, maior também o número de feixes formados e mais próximos eles estarão; com isso, a distância de deslocamento de um feixe para o outro será menor.

Quanto ao elemento pega do feixe, no subsistema 1, na extração o Skidder, ao pegar o feixe pela própria ação da pinça traseira, de certa forma o compactava mais em certos casos, sobrepondo algumas árvores em relação às outras; assim, o slingshot, ao efetuar a pega das árvores no feixe para iniciar o processamento, tinha que, em alguns casos, realizar alguns movimentos para desvencilhar uma árvore da outra, o que aumentava o tempo total do elemento. No subsistema 2 o operador do Feller-Buncher era orientado para formar feixes com menor número de árvores, de modo que estas ficassem mais dispersas no feixe, facilitando a pega pelo 'slingshot'. O ciclo operacional total do 'slingshot' gastou, em média, 63,53 e $66,91 \mathrm{~s}$, nos subsistemas 1 e 2 , respectivamente.

Na Figura 3 se observa a distribuição dos elementos parciais que compuseram o ciclo operacional do 'slingshot' no subsistema 3 , cujos valores correspondem a um ciclo operacional de corte composto, em média, de 7 árvores. O elemento busca e corte foi o mais representativo, vindo em seguida o elemento processamento e, juntos, representavam cerca de $75 \%$ do tempo do ciclo total. Os elementos deslocamento sem carga e deslocamento carregado representaram, juntos, cerca de $21 \%$

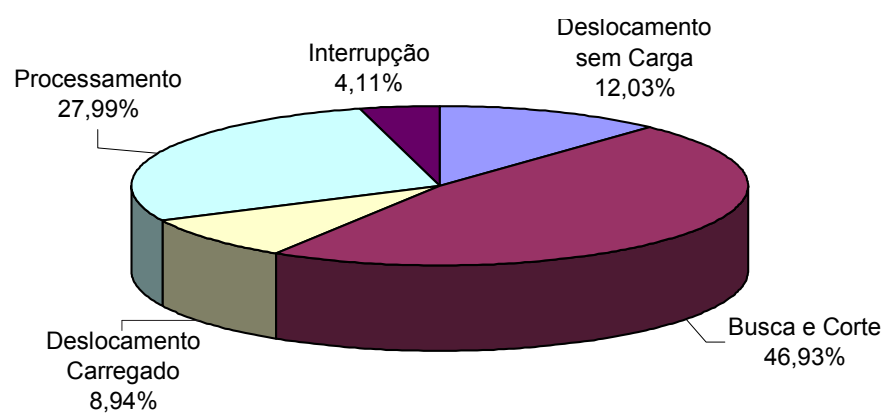

Figura 3. Composição percentual do tempo total do ciclo operacional do Slingshot no subsistema 3

do tempo total do ciclo, sendo o restante, cerca de $4 \%$, gastos com interrupções operacionais. O ciclo operacional do 'slingshot' no subsistema 3, em razão do conjunto global dos dados gastou, em média, $138,82 \mathrm{~s}$ ou $2,31 \mathrm{~min}$.

Tabela 2. Produtividade do 'slingshot' em função do subsistema de colheita

\begin{tabular}{ccc}
\hline Subsistema & Árvore $\mathrm{h}^{-1}$ & $\mathrm{~m}^{3} \mathrm{~h}^{-1 *}$ \\
\hline 1 & 624 & 41,41 \\
2 & 526 & 35,02 \\
3 & 198 & 13,27 \\
\hline *cc - com casca & &
\end{tabular}

\section{Produtividade}

$\mathrm{Na}$ Tabela 2 tem-se a produtividade do 'slingshot' em termos de árvores abatidas e metros cúbicos com casca, por hora efetiva de trabalho.

O desempenho do equipamento no subsistema 3 mostrouse bem inferior aos subsistemas 1 e 2 , em termos de número de árvores abatidas por hora efetiva, devido à função dupla (derrubada e processamento) exercida pelo 'slingshot' neste subsistema. $\mathrm{O}$ 'slingshot' apresentou, no subsistema 3, tempo médio por ciclo de 118,51 e 107,47\%, maior que nos subsistemas 1 e 2 , respectivamente, gerando rendimento inferior em 215,30 e $165,56 \%$ em termos de árvores abatidas por hora de efetivo trabalho, para os subsistemas 1 e 2 , respectivamente.

Analisando-se o rendimento em termos de volume por unidade de tempo, notou-se que o subsistema 1 teve rendimento superior em 18,25\% em relação ao subsistema 2; esta diferença se deveu ao menor tempo total e ao maior número de árvores abatidas por ciclo, gerando menor tempo médio por árvore neste subsistema. O subsistema 3 apresentou queda de 212,05 e 163,90\% em relação aos subsistemas 1 e 2, respectivamente, cuja causa foi a mesma já descrita. Com o aumento no volume médio por árvore, ocorreu aumento no rendimento do slingshot, em termos de volume por unidade de tempo, independentemente do subsistema de colheita.

\section{Custo operacional}

Para os subsistemas 1 e 2 e se considerando uma taxa de juros de $12 \%$ a.a. e uma eficiência operacional de $77 \%$, chegou-se ao custo/hora de trabalho efetivo de US\$68,45. Os custos fixos corresponderam, neste caso, a mais ou menos $43,83 \%$, e os custos variáveis, a aproximadamente $54,98 \%$ dos custos totais, respectivamente; o custo de administração foi da ordem de 1,20\% dos custos totais (Figura 4). 

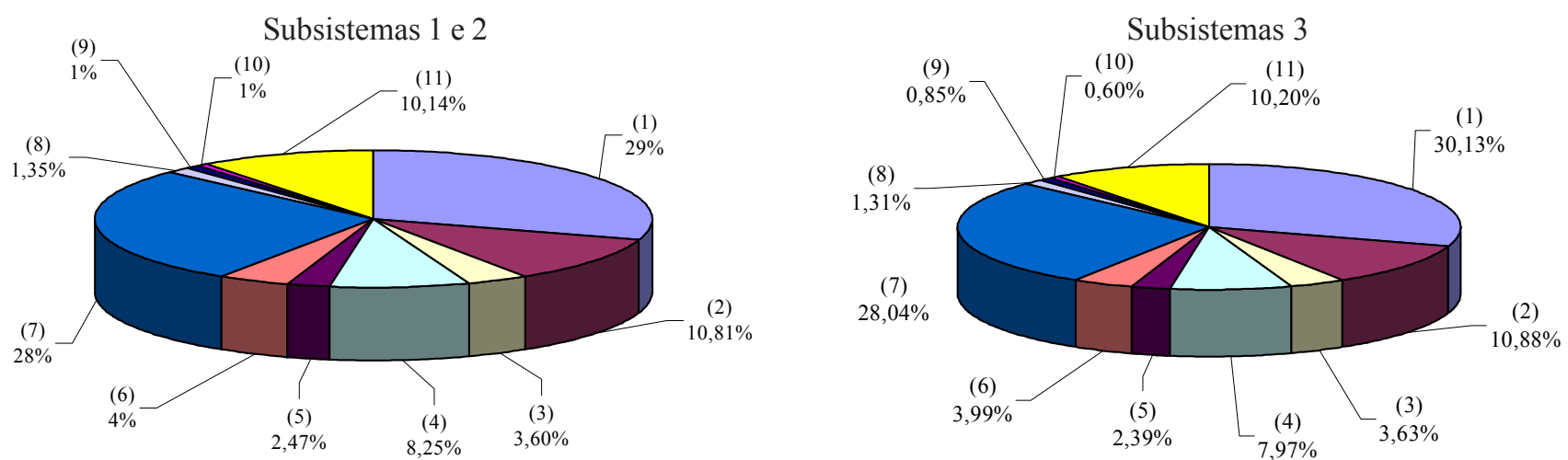

(1) Depreciação; (2) Juros; (3) Seguros; (4) Combustível; (5) Lubrificante; (6) Óleo hidrálico; (7) Manutenção e reparos; (8) Pneus; (9) Custo transporte pessoal; (10) Custo transporte máquinas; (11) Mão-de-obra.

Figura 4. Distribuição percentual dos itens que compõem o custo operacional do 'slingshot' nos subsistemas em que ele atuou

No caso do subsistema 3 e levando em conta a mesma taxa de juros e uma eficiência operacional de $74 \%$, chegou-se ao custo $\mathrm{h}^{-1}$ efetivamente trabalhada, de US\$70,78. Os custos fixos e variáveis, neste caso, corresponderam a aproximadamente $44,05 \%$ e $54,63 \%$ dos custos totais, respectivamente; o custo de administração foi da ordem de $1,33 \%$ dos custos totais (Figura 4).

\section{Custo de produção e rendimento energético}

Como o custo operacional e o consumo de combustível do slingshot foram considerados os mesmos para os subsistemas 1 e 2 , o que determinou a variação no custo de produção e no rendimento energético foi a produtividade alcançada pelo slingshot em cada subsistema. O maior custo de produção e o pior rendimento energético no subsistema 3 foram devidos ao maior custo operacional e, sobretudo, à baixa produtividade do slingshot em relação aos outros subsistemas analisados (Tabela 3).

Tabela 3. Custo de produção e rendimento energético do Slingshot, em função do subsistema de colheita

\begin{tabular}{ccc} 
Subsistema & $\begin{array}{c}\text { Custo de Produção } \\
\text { US } \$ \mathrm{~m}^{-3} \mathrm{cc}^{*}\end{array}$ & $\begin{array}{r}\text { Rendimento Energético } \\
\mathrm{g} \mathrm{kW}^{-1} \mathrm{~m}^{3} \mathrm{cc}^{*}\end{array}$ \\
\hline 1 & 1,67 & 3,60 \\
2 & 2,02 & 4,37 \\
3 & 5,47 & 11,42 \\
\hline *cc - com casca & &
\end{tabular}

O custo de produção e o rendimento energético decresceram à medida que se aumentou o volume médio por árvore, em virtude do aumento na produtividade do slingshot quando se aumentou o volume médio por árvore.

\section{CONCLUSÕES}

1. O elemento processamento nos subsistemas 1 e 2 abrangeu mais da metade do ciclo operacional sendo esses tempos muito próximos.

2. Os elementos que apresentaram as maiores diferenças foram deslocamento da máquina-base, que correspondeu a 4,89 e $10,80 \%$, nos subsistemas 1 e 2 , respectivamente, e o elemento pega do feixe, correspondente a 21,37 e $13,47 \%$, respectivamente.
3. No subsistema 3 os elementos busca e corte e processamento representaram, juntos, cerca de $75 \%$ do tempo do ciclo total.

4. A produtividade do 'slingshot' no subsistema 3 mostrouse bem inferior aos subsistemas 1 e 2 , em termos de número de árvores abatidas e metros cúbicos por hora efetiva, devido à função dupla (derrubada e processamento) exercida pelo 'slingshot'.

5. Nos subsistemas 1 e 2 chegou-se a um custo operacional de US\$ 68,45 . No caso do subsistema 3 , esse custo foi de US\$ 70,78.

6. Os custos de produção do 'slingshot' foram de US\$ 1,67 ; 2,02 e $5,47 \mathrm{~m}^{-3}$ (com casca), nos subsistemas 1,2 e 3, respectivamente. $\mathrm{O}$ rendimento energético foi de 3,60; 4,37 e $11,42 \mathrm{~g} \mathrm{~kW}^{-1} \mathrm{~m}^{-3}$ (com casca).

\section{LITERATURA CITADA}

Bagio, A.J.; Stohr, G.W.D. Resultados preliminares de um levantamento dos sistemas de exploração usados em florestas implantadas no sul do Brasil. Revista Floresta, Curitiba, v.9, n.2, p.76-96, 1978.

Barnes, R.M. Motion and time study: design and measurement of work. 6.ed. New York: John Willey \& Sons, 1968. 799p.

DURATEX, Equipe técnica. Colheita da madeira em florestas com baixo volume por árvore. In: Simpósio Brasileiro sobre Colheita e Transporte Florestal, 4, 1999, Campinas. Anais.....Campinas: Sociedade de Investigações Florestais, 1999. p.54-72.

Garlipp, R.C.D. O boom da certificação florestal: é preciso garantir a credibilidade. Revista Silvicultura, São Paulo, v.17, n.61, p.17-22, 1995.

Machado, C.C. Planejamento e controle de custos na exploração florestal. Viçosa: UFV, Imprensa Universitária, 1984. 138p.

Tanaka, O.P. Exploração e transporte da cultura do eucalipto. Informe Agropecuário, Belo Horizonte, n.141, p. 24-30, 1986.

Valverde, S.R. A contribuição do setor florestal para o desenvolvimento socioeconômico: uma aplicação de modelos de equilíbrio multissetoriais. Viçosa, UFV, 2000. $105 \mathrm{p}$. Tese Doutorado 